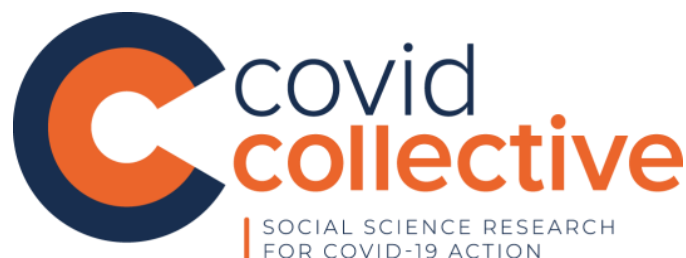

\section{Local knowledge and participation in the Covid-19 response}

\author{
Amanda Lenhardt \\ Research Insights International \\ 22 May 2021
}

\section{Questions}

- What literature is there on the benefits of engaging local knowledge in response to the socioeconomic impacts of Covid-19?

- Are there examples of policies or programmes that have successfully integrated local realities in selected Covid Collective countries?

\section{Contents}

1. Summary

2. Decolonial perspectives on the covid-19 pandemic

3. Background to local knowledge and participation in recovery efforts

4. Decentralised decision-making

5. Technological adaptations to engage local communities

6. Southern-led research and participatory research methods in the context of covid-19

7. References

The Covid Collective helpdesk service provides brief summaries of current research, evidence, and lessons learned. Helpdesk reports are not rigorous or systematic reviews; they are intended to provide an introduction to the most important evidence related to a research question. They draw on a rapid desk-based review of published literature and consultation with subject specialists.

This Helpdesk report was commissioned through the Covid Collective based at the Institute of Development Studies (IDS) and is funded by the UK Foreign Commonwealth and Development Office (FCDO) The Collective brings together the expertise of, UK and Southern based research partner organisations and offers a rapid social science research response to inform decision-making on some of the most pressing Covid-19 related development challenges. The views and opinions expressed do not necessarily reflect those of FCDO, the UK Government, or any other contributing organisation. For further information, please contact covidcollective@ids.ac.uk 


\section{Summary}

Covid-19 response and recovery risks inheriting the longstanding history of imposed humanitarian objectives and activities by external actors, leading to limited local ownership and reduced effectiveness. "During public health emergencies, such as the current COVID-19 [crisis], communities are often poorly involved in the planning and implementation of interventions, yet their commitment is fundamental to control outbreaks (Anoko et al., 2020, p.1). There is, however, a wealth of guidance building on lessons learned from past mistakes and evidence generated by effective participatory interventions. Many observers have noted that the localised nature of the effects of the pandemic may open space for community participation in relief and recovery efforts, with potential longer-term contributions to the decolonisation of knowledge and participation in development (Leach et al., 2020; Ndlovu-Gatsheni, 2021; Rutazibwa, 2020). This shift may also open opportunities to address longstanding inequalities and exclusion where response and recovery activities actively include those at risk of being left behind as empowered partners in recovery processes.

This report explores approaches to participation in humanitarian response and evidence on the contributions of community engagement in effective response and recovery efforts. It begins with a brief overview of decolonial perspectives on the Covid-19 pandemic to situate participation in the wider context and history of humanitarian and development theory and practice. This is followed by a brief summary of evidence on the role of participation in humanitarian activities and situates the now ubiquitous concept of 'Building Back Better' (BBB) in the discussion of participatory crisis response and recovery. The remaining sections of the report introduce participatory approaches that have been applied through the Covid-19 pandemic: decentralised decision-making, technological adaptations to engage local communities, and Southern-led research and participatory research methods.

\section{Key findings:}

- Failures to learn from 'Southern' knowledge and experience has come under criticism and has prompted renewed calls for decolonial, post-colonial and post-development approaches to Covid-19 response, recovery, and beyond.

- There is a strong evidence base on the importance of community participation in disaster response to ensure effective, inclusive recovery and promote longer-term resilience, but participation of affected communities in humanitarian activities remains limited.

- There have been mixed experiences with regards to centralised versus decentralised decision-making. However, there is a recognition that local-level governments are able to be more responsive to communities, especially when coupled with accountability mechanisms enabling communities to feedback on local government response.

- Innovations in the use of social media, traditional media, and other technological adaptations have been used to communicate up-to-date guidance on Covid-19, to understand the needs of local communities, and develop tailored government responses.

- There have been some reports of the pandemic opening up space for Southern researchers to lead in research, though it is too soon to know what effect this may have on the effectiveness of the Covid-19 response and whether this will yield longer-term power shifts in research.

- There have been adaptations of traditional research methods due to travel restrictions and social distancing measures limiting face-to-face contact between researchers. These 
have prompted innovations in participatory research approaches that encourage greater engagement with participants while limiting travel. These approaches also present challenges, particularly around accessibility for certain groups and emerging ethical issues related to participatory research by distance and added strain on participants.

It is important to note that these changes are occurring in an era of increased repression, authoritarianism, and misinformation in many countries (V-Dem, 2021). Following a decade of decline in liberal democracy globally, particularly in Asia-Pacific, Central Asia, Eastern Europe, and Latin America, 2020 saw a proliferation of civil liberties violations (V-Dem, 2021). While the immediate effects of emergency measures may be limited to the containment period of the pandemic, media restrictions and emergency measures with no time limit could have longer-term consequences (V-Dem, 2021). Restrictions on civil liberties, freedom of expression and on media could negatively impact community participation in recovery efforts and have longer-term effects on participatory governance and accountability.

\section{Decolonial perspectives on the Covid-19 pandemic}

This section explores four factors that a decolonial perspective on the Covid-19 pandemic encourages us to consider in Covid response and recovery efforts:

(1) Inequalities between and within countries leading up to the pandemic have led to uneven social and economic impacts.

(2) These inequalities will affect who is engaged in the design and implementation of recovery and response efforts.

(3) Existing development paradigms are rooted in a colonial legacy of power and resource distribution.

(4) Knowledge from the 'global South' is integral to local response and recovery but can also be translated for use in the global 'North'.

The rapid spread of Covid-19 around the world has been linked to the interconnectedness of human society through globalisation, while the uneven effects of the pandemic have been linked to the persistent unequal power and resource distributions that divide countries and social groups within them (Mas-Coma et al., 2020; Ndlovu-Gatsheni, 2021; Shrestha et al., 2020). A number of observers note that the pandemic has shone a light on systemic inequalities within and between countries, revealing highly divergent capacities to mitigate shocks of this nature (Maestripieri, L., 2021; Ndlovu-Gatsheni, 2021; Phillips et al., 2020; Rutazibwa, 2020). The dynamics that have shaped these unequal experiences of the pandemic are a critical frame of reference to observe who is engaged in response and recovery efforts, and what form that recovery will ultimately take.

The disproportionate effects of the pandemic on historically marginalised groups have prompted a number of scholars to draw links between Covid-19 and racial capitalism (Maraj \& Kerrigan, 2020; Pirtle, W., 2020; Ndlovu-Gatsheni, 2021). The racial capitalist view holds that "the development, organisation, and expansion of capitalist society pursued essentially racial directions, so too did social ideology" (Robinson, quoted in Melamed 2015, p.77). In an already widely cited paper by Pirtle (2020), she opens with the observation that "racial capitalism is a fundamental cause of disease in the world and will be a root cause of the racial and socioeconomic inequities in COVID-19 that we will be left to sort out when the dust settles" (p.504). Ndlovu-Gatsheni extends the analysis of racial capitalism to the creation of "geographies 
of wealth and geographies of scarcity, maldevelopment, and underdevelopment", arguing that weak public health systems in Africa are in part due "to two-decade-long havoc wreaked on them by imposed structural adjustment programmes" (2020, p.277). The same link had been made to under-funded health systems and "uneven social and economic fallout from Covid-19" in the Caribbean region (Maraj \& Kerrigan, 2020).

The stark global inequalities highlighted by the Covid-19 pandemic has ignited discussions among decolonial, post-colonial and post-development scholars around agency and power relations in the creation and application of knowledge in Covid-19 recovery (Kwok, 2020; Leach et al., 2020; Ndlovu-Gatsheni, 2021; Rutazibwa, 2020, Vazquez quoted in Rutazibwa, 2020; Westboy \& Harris, 2020). These scholars have initiated conversations on the epistemological foundations upon which Covid-19 response and recovery, and development more broadly, will be built. Rutazibwa (2020) has argued that failures in international coordination and lack of support to lower-income countries have highlighted colonial legacies in unequal resource capacities and global solidarity. She also commented that "individual and local community initiatives painfully and sharply highlight where our structures and national and global systems of governance murderously fall short". Many are now asking whether these revealed inadequacies may open the space for a reimagination of agency and power in the conceptualisation and realisation of development.

The hegemony of 'Northern' knowledge in the Covid-19 response to date, and failures to learn from 'Southern' knowledge and experience, has come under criticism by many of these decolonial and post-colonial scholars (Leach et al., 2020; Ndlovu-Gatsheni, 2021; Rutazibwa, 2020). Ndlovu-Gatsheni captures the breadth of these approaches in the context of the Covid-19 crisis in his observation that:

"Calls and initiatives to take "endogenous knowledge" (Hountondji, 1997), the "southern theory" (Connell, 2007), "theory from the South" (Comaroff \& Comaroff, 2012), "epistemologies from the South" (Santos, 2014, 2018), and "epistemic freedom" (NdlovuGatsheni, 2018) seriously become very important now when the rest of the world is experiencing part of what the people of the Global South have been experiencing for over 500 years."

(Ndlovu-Gatsheni, 2021, p. 371)

With current Overseas Development Assistance (ODA) and international engagement in low- and middle-income countries largely focused on containing the virus, there is a risk of crowding out locally generated ideas, resourcing and innovations. Curtailing local knowledge and experience, and meaningful participation of affected communities in the response risks a return to old colonial models and that have shaped humanitarian and development practice.

\section{Background to local knowledge and participation in recovery efforts}

\section{Principles of participation in humanitarian response}

There is extensive literature on the role of community participation in humanitarian activities and evidence on the potential contribution of community engagement in crisis response and recovery (for reviews of this literature and evidence, see Brown et al., 2014; Rass et al., 2020; Bealt \& Masouri, 2018). Evidence indicates that local participation can 
contribute to more effective information sharing where community groups have a more specific understanding of the affected setting (Bealt \& Masouri, 2018, Brown et. al, 2014), can mobilise local "life and livelihoods saving networks in the area" (Bealt \& Masouri, 2018, p.139), while also promoting community empowerment, resilience, and trust. These effects of community participation are seen as important outcomes in their own right (Brown et al., 2014), and critical to the mitigation of future adverse events (Bealt \& Masouri, 2018, p.140).

Despite the strong evidence-base on the benefits of community participation in humanitarian response, a 2008 review found limited integration of local participation in humanitarian activities beyond initial consultation in the project design phase (see Figure 1) (Brown et al., 2014). It has been suggested that since this 2008 review, there has been an "increase in interest in establishing mechanisms for two-way communication between aid recipients and agencies, with widespread experimentation and innovative uses of mobile phones, text messaging, social media, interactive voice response, and other new technologies (Brown et al, 2014). An update to this 2008 review, comparing the intervening years leading up to the pandemic and covering the response and recovery phase, would be useful to observe the results of this 'increased interest' and whether any major shifts were made as a result of the unique nature of the Covid-19 crisis.

Figure 1: Levels of types of engagement at different phases of the project cycle

\begin{tabular}{|l|l|l|l|l|l|}
\hline Project phase & Diagnosis & $\begin{array}{l}\text { Design and } \\
\text { preparation }\end{array}$ & Implementation & Monitoring & Evaluation \\
\hline $\begin{array}{l}\text { Degree of } \\
\text { engagement }\end{array}$ & & & & & \\
\hline $\begin{array}{l}\text { Type of } \\
\text { engagement }\end{array}$ & $\begin{array}{l}\text { Consists mainly } \\
\text { of providing } \\
\text { data }\end{array}$ & Very rare & $\begin{array}{l}\text { Frequent in the } \\
\text { form of in-kind } \\
\text { contributions or } \\
\text { labour }\end{array}$ & Rare & \\
\hline
\end{tabular}

Source: Brown et al., 2014. (CC BY-NC 3.0)

\section{Participation and the concept of 'building back better'}

The concept of 'building back better' (BBB) is now ubiquitous in discussions of Covid-19 response and recovery, but the concept has roots in the discourse around humanitarian response dating back to the 2006 Indian Ocean Tsunami (Fernandez \& Ahmed, 2019). First coined in a report titled "Building Back Better" by the United Nations Secretary General's Special envoy for the Tsunami recovery, former U.S. President Bill Clinton, the term went on to become "the mantra of post-disaster reconstruction programs" (Fernandez \& Ahmed, 2019, p.1). The original 2006 report had local participation in humanitarian response and recovery at the centre of most of its ten "Key Proposition for Building Back Better": 
Table 1: U.N. Secretary-General's Special Envoy for Tsunami Recovery's key propositions for Building Bank Better

\begin{tabular}{|c|c|}
\hline Proposition 1 & $\begin{array}{l}\text { Governments, donors and aid agencies must recognise that families and communities } \\
\text { drive their own recovery. }\end{array}$ \\
\hline Proposition 2 & Recovery must promote fairness and equity. \\
\hline Proposition 3 & Government must enhance preparedness for future disasters. \\
\hline Proposition 4 & $\begin{array}{l}\text { Local governments must be empowered to manage recovery efforts, and donors must } \\
\text { devote greater resources to strengthening government recovery institutions, especially } \\
\text { at the local level. }\end{array}$ \\
\hline Proposition 5 & Good recovery planning and effective coordination depend on good information. \\
\hline Proposition 6 & $\begin{array}{l}\text { The U.N., World Bank and other multilateral agencies must clarify their roles and } \\
\text { relationships, especially in addressing the early stage of a recovery process. }\end{array}$ \\
\hline Proposition 7 & $\begin{array}{l}\text { The expanding role of NGOs and the Red Cross/ Red Crescent Movement carries } \\
\text { greater responsibilities for quality in recovery efforts. }\end{array}$ \\
\hline Proposition 8 & $\begin{array}{l}\text { From the start of recovery operations, government and aid agencies must create the } \\
\text { conditions for entrepreneurs to flourish. }\end{array}$ \\
\hline Proposition 9 & $\begin{array}{l}\text { Beneficiaries deserve the kind of agency partnerships that move beyond rivalry and } \\
\text { unhealthy competition }\end{array}$ \\
\hline Proposition 10 & Good recovery must leave communities safer by reducing risks and building resilience. \\
\hline
\end{tabular}

Source: Office of the U.N. Secretary-General's Special Envoy for Tsunami Recovery (2006).

The concept of BBB has been a leading principle applied to disaster response since its emergence, including the 2010 Haiti earthquake, the 2015 Nepal earthquake, and was eventually adopted as a formal priority in the Sendai Framework for Disaster Risk Reduction (2015-2030). A well-known framework developed by Mannakkara \& Wilkinson (2014) proposes indicators on BBB around disaster risk reduction, community recovery, and effective implementation which has been used to evaluate a range of disasters since its publication (Fernandez \& Ahmed, 2019). More recently, with more attention on BBB than ever before, the concept has been evolving to "incorporate ideas about building forward, and differently [with a] central message implied: crisis disrupts the status quo, and potentially opens spaces to do things differently (Taylor \& McCarthy, 2021, p.12)

\section{Evidence on participation from past crises}

Community engagement in the 2014-16 and 2018-2020 Ebola responses in Africa has shown to be both integral to the immediate response and, to yield longer term benefits for community members and to be important for the maintenance of community structures that can respond to future crises (Anoko et al., 2020). "Experiences of community engagement and co-construction during Ebola response have shown that when communities were involved in problem analysis and co-construction of solutions, they took ownership of the response interventions and committed to efforts to curb the epidemic" (Anoko et al., 2020). Drawing lessons from this experience, Anoko et al. (2020) recommend recruiting local staff in response activities, involving grass-roots leaders in the preparation and implementation of the response, and mobilising any communities resistant to the response to overcome dissent and promote the sustainability of response structures (p.1). They also point to the potential for job 
creation and skills-building through relief efforts by investing relief funds in local staff whose livelihoods as most likely disrupted.

"For a population and especially for young people who are facing unemployment and whose socioeconomic demands are not always met, the response can be an opportunity to find jobs and relieve their suffering. During the Ebola outbreak response, partners often recruit young people and women into the response services; for example, youth and women employed in the neighbourhoods where response structures (treatment units, points of control/points of entry) have been built. This has helped facilitate community acceptance of these new structures, preventing reluctance, vandalism and violence against the health teams".

(Anoko et al., 2020, p.3)

The inclusion of all affected groups in crisis response and recovery is critical as failure to acknowledge pre-crisis structural inequalities and exclusionary norms risks exacerbating these inequalities through the recovery process (GFDRR, 2018). A recent achievement in the inclusion of women in humanitarian response occurred in the Sudan peace negotiations that culminated in a peace agreement in 2020. Following a history of women's exclusion from peace negotiations globally despite a 2000 U.N. resolution on women's participation in peace processes (S/RES/1325), the active engagement of women's groups in Sudan's locally led peace process has been marked as a positive watershed moment in women's inclusion (Awad, 2020). Among the achievements from women's participation in this process:

"The peace agreement reaffirms the commitment of the transitional government's constitutional document to secure a $40 \%$ quota for women participation in the national and regional governments as well as in parliament. It also mentions equal access to the mechanisms of reparation, restitution and transitional justice... Women in conflict areas all over Sudan have an unprecedented opportunity to challenge the patriarchy's social and political norms through the achievements of these agreements"

(Awad, 2020)

\section{Decentralised decision-making}

There have been mixed experiences across countries with regards to centralised versus decentralised decisions-making. However, there is a recognition that local-level governments are able to be more responsive to communities (Kosec \& Mogues, 2020). China began with a decentralised approach, with negative outcomes from Wuhan province, before moving to a centralised approach, while India moved from a central responsive to a more decentralised approach, maintaining a low spread of the disease through 2020 (Kosec \& Mogues, 2020). A review of decentralised decision-making in the Covid-19 response in Bengaluru (India), Medellin (Colombia) and Cape Town (South Africa) found that cities took a more decisive role in Covid-19 response than they have tended to have in development decisionmaking leading up to the pandemic (Mejia-Dugand et al., 2020). In Bengaluru and Medellin, the authors find that city-level government adopted a nearly autonomous approach to Covid-19 management, independent of national-level directive. In Cape Town, national and provincial-level directives were seen to be serving as the main policy influence. The authors also argue that local engagement has been critical in Covid-19 responses and that the partnerships that have been created throughout the crisis between different levels of decision-making can be built upon beyond the Covid-19 crisis (Mejia-Dugand et al., 2020) 
Reviewing the experience of decentralisation in three countries with some degree of decentralisation - Ethiopia, Kenya, South Africa - Steytler concludes that "the impact of the pandemic on decentralised governance largely depends on who are the decisionmakers" (quoted in Stevens, 2020). In South Africa, the central government played a dominant role in the country's response through a national disaster advisory body, whose imposition eventually led some to question the body's legal and constitutional status (Stevens, 2020). In Ethiopia, it has been argued that states were slow to respond, in part due to the historically strong central government, which has led states to wait for central government directives before acting (Ayele, quoted in Stevens, 2020). In Kenya, a new precedent for dialogue between the central government and states emerged from the pandemic, and calls have been made for the practice to continue beyond the pandemic (Stevens, 2020).

There are competing views as to the effectiveness of decentralised vaccine rollouts, but there appears to be agreement around the need to include local communities in the design and implementation of vaccination programmes (Burgess et al., 2021). Burgess et al. make the critical observation that the Covid-19 vaccine rollout is taking place at a time when trust in government is low in many countries. They note that the very groups that have been disproportionately affected by the pandemic due to structural inequalities are "now being asked to trust the same structures that have contributed to their experiences of discrimination, abuse, trauma and marginalisation in order to access vaccines and the benefit the wider population" (2021, p.8). The authors draw on lessons learned from past immunisation programmes to show how community engagement can improve vaccine uptake:

"Nigeria's polio eradication campaigns were eventually turned around through widespread community dialogues, which helped to foster social learning, establish equity, and generate and restore trust and participation in the programme... India's polio eradication efforts and rubella in the Americans, are rooted in wide-scale social mobilisation and systems strengthening... Weaknesses in implementation of a wide-scale COVID-19 vaccination strategy will reduce the efficacy of the vaccine as reported in clinical trials and underlines the need for investment to promote public confidence in vaccines and maintain other COVID-19 mitigation measures."

Burgess et al., 2021, p.9

\section{Technological adaptations to engage local communities}

Innovations in the use of social media have been used as a tool to communicate up-todate guidance on Covid-19, to understand the needs of local communities, and to develop tailored government responses. In Rwanda, for example, the government adopted innovative strategies such as "remote case identification, use of a toll-free hotline, a national WhatsApp number, and drones for information dissemination" (Karim et al., 2021, p.1. Karim et al. argue that "robust communication and community engagement plans using social media platform have also helped combat misinformation and increase public knowledge about the disease (2021, p.2). Early in the pandemic in April 2020, The Indian Ministry of Health and Family Welfare introduced an online platform to 'enable transparent e-governance delivery in real-time and [to] answer citizen queries swiftly' (Rissadiary, 2020). The innovative platform processes large volumes of tweets, converts them into tickets, and assigns them to the relevant authority for a response.

More traditional forms of communication, such as radio, have also been harnessed to promote dialogue between policymakers, services providers, and local communities. In 
Ethiopia, call-in radio shows were promoted by the Ethiopia Social Accountability Program (ESAP) to support citizens to share problems in local service delivery and to engage community members in the process of finding solutions to these problems (World Bank, 2021). Building on earlier achievements of the ESAP programme which had been found to generate positive returns on investment through spending with citizen oversight, the radio programmes' reach was nearly doubled from 317 woredas to 729 woredas. "The program is also working to engage with women on issues related to female empowerment" (World Bank, 2021). Radio programmes can be particularly effective in accessing harder to reach communities, such as those in remote areas with limited phone network access, or those with limited access to technology.

\section{Southern-led research and participatory research methods in the context of Covid-19}

There have been some reports of the pandemic opening up space for Southern researchers to lead in research initiatives and for Southern-based research institutions to re-imagine their strategic priorities beyond those set by international agendas (Brooks, 2020). Travel restrictions preventing 'Northern' researchers from taking part in in-person research in the 'South' has been a "wake-up call" as African research partners "quickly stepped into lead roles when UK-led principal investigators were no longer able to fly out" (Brooks, 2020). This has been described as "a signal that African researchers should not only be leading on ambitious projects but also be setting their agenda and defining what research in undertaken in the first place (Brooks, 2020). Linking to the decolonial agenda described above, some observers predict that this disruption to the normal way of working in development research might offer an opportunity to "work with research partners and participants in a more sustainable and equitable way" (Pinet \& Leon-Himmelstine, 2020)

There have been adaptations of traditional research methods due to travel restrictions and social distancing measures limiting face-to-face contact between researchers, often 'Northern'- based, and research participation. Many researchers have explored the opportunities for better participation through these adaptations, and in some cases, decolonial approaches have been tested. A review of participatory research approaches adopted during Covid-19 identified the adaptation of telephone interviews, text-based interviews and interviews using WhatsApp, photo voice, audio diaries, and online workshop and focus group discussions being used (Hall et al., 2021). Various benefits for participation were noted among studies adopting these approaches. Text-based focus groups were observed to offer greater confidentiality which could be used to discuss more sensitive topics. Audio diaries were found to encourage participants to describe and reflect on their experiences and understanding of the pandemic, allowing them to process their experiences. Video conferencing was found to make participants more comfortable in the discussion by allowing them to participate in their own familiar surroundings (Hall et al., 2021). There were, however, a number of challenges identified in these methods, including unequal access to networks and devices, the prohibitive costs of data for some participants, limited technological literacy, lack of control over the research, and access constraints for people with disabilities (Hall et al., 2021). Further ethical concerns have been raised around research during the Covid-19 crisis when participants may be under added strain and where meaningful participation at a distance may be difficult (Hall et al., 2021). Wells et al. propose a set of lessons learned from past participatory research to apply to the current context including co-equal leadership, respect of differences in culture, authentic partnerships, awareness of the effect of terminologies used to describe affected groups, two-way analysis 
aligned with community priorities, trust-building through on-going engagement, and an emphasis on equality and equity at all stages (2020).

\section{References}

Alizada, N., Cole, R., Gastaldi, L., Grahn, S., Hellmeier, S., Kolvani, P., Lachapelle, J., Lührmann, A., Maerz, S., Pillai, S. \& Lindberg, S. (2021) Autocratization Turns Viral. Democracy Report 2021. University of Gothenburg: V-Dem Institute. https://www.vdem.net/files/25/DR\%202021.pdf

Anoko, J., Barry, B., Boiro, H., Diallo, B., Diallo, A., Belizaire, R., Keita, M., Djingarey, M., N'da, M., Yoti, Z., Fall, I, Talisuna, A. (2020). Community engagement for successful COVID-19 pandemic response: 10 lessons from Ebola outbreak responses in Africa. BMJ Global Health, $4(7)$

Awad, N. (2020). Sudanese women show that peace requires participation not just representation. open Democracy, https://www.opendemocracy.net/en/north-africa-westasia/sudanese-women-show-peace-requires-participation-not-just-representation/

Bealt, J., Mansouri, S. (2018). From disaster to development: a systematic review of communitydriven humanitarian logistics. Disasters, 42(1), 124-148

Brooks, J. (2020). How will Covid-19 affect research for development. Research Professional News. https://www.researchprofessionalnews.com/rr-funding-know-how-working-internationally2020-how-will-covid-19-affect-research-for-development/

Brown, D., Donini, A. \& Knox Clarke, P. (2014). Engagement of crisis-affected people in humanitarian action. Background Paper of ALNAP's 29th Annual Meeting, 11-12 March 2014, Addis Ababa. London: ALNAP/ODI

Burgess, R., Osborne, R., Yongabi, K., Greenhalgh, T., Gurdasani, D., Kang, G., Falade, A., Odone, A., Busse, R., Martin-Moreno, J., Reicher, S., McKee, M (2021). The COVID-19 vaccines rush: participatory community engagement matters more than ever. The Lancet, 397 (10268), 810.

Comaroff, J., \& Comaroff, J. L. (2012). Theory from the south or, how EuroAmerica is evolving toward Africa. Paradigm Publishers: Oxon, New York.

Fernandez, G. \& Ahmed, I. (2019). "Build back better" approach to disaster recovery: Research trends since 2006. Progress in Disaster Science, 1, 100003.

Global Facility for Disaster Reduction and Recovery (GFDRR) (2018). Gender Equality and Women's Empowerment in Disaster Recovery. GFDRR: Washington, D.C.

Hall, J, Gaved, M., Sargent, J. (2021). Participatory Research Approaches in Times of Covid-19: A Narrative Literature Review. International Journal of Qualitative Methods, 20, 1-15

Hountondji, P. (Ed.) (1997). Endogenous knowledge: Research trials. CODESRIA Book Series

Karim, N., Jing, L., Lee, J., Kharel, R., Lubetkin, D., Clancy, C., Uwanahoro, D., Nahayo, E., Biramahire, J., Aluisio, A. \& Ndebwanimana, V. (2021). Lessons Learned from Rwanda: innovative Strategies for Prevention and Containment of COVID-19. Annals of Global Health, $87(1)$ 
Kosec, K. \& Mogues, T. (2020). Should low-income countries decentralize their COVID-19 response? IFPRI Blog, Jul 8, 2020. https://www.ifpri.org/blog/should-low-income-countriesdecentralize-their-covid-19-responses

Kwok, H. (2020). Beyond the anti-racist reason: a post-colonial perspective on pandemic politics. Health Sociology Review, 29(2), 122-130

Leach, M., MacGregor, H., Scoones, I. \& Wilkinson, A. (2021). Poast-pandemic transformation: How and why COVID-19 requires us to rethink development. World Development, 138 (2021)

Maestripieri, L. (2021). The Covid-19 Pandemics: why Intersectionality Matters. Frontiers in Sociology, 6, 642-662

Mannakkara, S. \& Wilkinson, S. (2014). Re-conceptualising "Building Back Better" to improve post-disaster recover. International Journal of Managing Projects in Business, 7(3).

Maraj, N. \& Kerrigan, D. (2020). COVID-19 and the impact of racial capitalism in the Caribbean. Dicover Society. https://archive.discoversociety.org/2020/04/06/covid-19-and-the-impact-ofracial-capitalism-in-the-caribbean/

Mas-Coma, S., Jones, M., Marty, A. (2020). COVID-19 and globalization. One Health, 9, 100132

Mejia-Dugand, S., Croese, S. \& Reddy, S. (2020). SDG Implementation at the Local Level: Lessons From Responses to the Coronavirus Crisis in Three Cities in the Global South. Frontiers in Sustainable Cities, 2 (598516)

Melamed, J. (2015). Racial Capitalism. Critical Ethnic Studies, 1(1), 76-85

Ndlovu-Gatsheni, S. (2020). Geopolitics of Power and Knowledge in the COVID-19 Pandemic: Decolonial Reflection on a Global Crisis. Journal of Development Societies, 36(4), 366-389

Office of the U.N. Secretary-General's Special Envoy for Tsunami Recovery (2006). Key Propositions for Building Back Better.

https://reliefweb.int/sites/reliefweb.int/files/resources/F7D5733098D2B78049257252002304DEFull\%20Report.pdf

Phillips, C., Caldas, A., Cleetus, R., Dahl, K., Declet-Barreto, J., Licker, R., Merner, L., OrtizPartida, J., Phelan, A., Spanger-Siegfried, E., Talati, S., Trisos, C. \& Carlson, C. (2020). Compound climate risks in the COVID-19 pandemic. Nature Climate Change, 10, 586-588

Pinet, M \& Leon-Himmelstine, C. (2020). How can Covid-19 be the catalyst to decolonise development research? From Poverty to Power. https://oxfamblogs.org/fp2p/how-can-covid-19be-the-catalyst-to-decolonise-development-research/

Pirtle, W. (2020). Racial Capitalism: A Fundamental Cause of Novel Coronavirus (COVID-19) Pandemic Inequities in the United States. Health Education \& Behvaiour, 47(4), 504-508.

Rass, E., Lokot, M., Brown, F., Fuhr, D., Asmar, M., Smith, J., McKee, M., Orm, I., Yeretzian, J., Roberts, B. (2020). Participation by conflict-affected and forcibly displaced communities in humanitarian healthcare responses: A systematic review. Journal of Migration and Heatlh, 1-2 (2020) 
Rissadiary (2020). Dr Harsh Vardhan launches 'COVID India Seva', and interactive platform for citizen engagement on \#COVID19. https://orissadiary.com/dr-harsh-vardhan-launches-covidindia-seva-an-interactive-platform-for-citizen-engagement-on-covid19/

Rutazibwa, O. (2020). The corona pandemic blows the lid off the idea of Western superiority. MO, https://www.mo.be/en/opinion/corona-pandemic-blows-lid-idea-western-superiority

Santos, B. de S. (2014). Epistemologies of the south: Justice against epistemicide. Paradigm Publishers: Oxon, New York.

Shrestha, N., Shad, M., Ulvi, O., Khan, M., Karamehic-Muratovic, A., Nguyen, U., Baghbanzadeh, M., Wardup, R., Aghamohammadi, N., Cervantes, D., Nahiduzzaman, K., Zaki, R., Haque, U. (2020). The impact of COVID-19 on globalization, One Health, 11, 100180

Stevens, C. (2020). African School on Decentralisation: The impact of Covid-19 on decentralisation in Africa. Local Government Bulletin, 15 (3)

Taylor, P. \& McCarthy, M. (2021). Introduction, Building a Better World: The Crisis and Opportunity of Covid-19. IDS Bulletin 52(1).

https://bulletin.ids.ac.uk/index.php/idsbo/article/view/3113

Well, K., Jones, F. \& Norris, K. (2020). Applying Community-Partnered Participatory Research Approaches to Develop COVID-19 Solutions. Ethnicity \& Disease, 30(3), 422-436.

Westboy, P. \& Harris, V. (2020). Community development 'yet-to-come' during the COVID-19 pandemic: from Derrida to Zuboff. Community Development Journal, 55(4), 553-569

World Bank (2021). Innovative Citizen Engagement in Ethiopia During the COVID-19 Pandemic: Radio Shows Promote Accountable Service Delivery. World Bank News.

https://www.worldbank.org/en/news/feature/2021/01/25/innovative-citizen-engagement-inethiopia-during-the-covid-19-pandemic-radio-shows-promote-accountable-service-delivery

\section{Suggested citation}

Lenhardt, A. (2021) Local knowledge and participation in the Covid-19 response. Covid Collective Helpdesk Report No. 5, Brighton, UK: Institute of Development Studies,

DOI: 10.19088/CC.2021.005

\section{About this report}

This report is based on 6 days of desk-based research. The Covid Collective research helpdesk provides rapid syntheses of a selection of recent relevant literature and international expert thinking in response to specific questions relating to international development. For any enquiries, contact Covid Collectivecovidcollective@ids.ac.uk.

This evidence summary was funded by the U.K. Government's Foreign, Commonwealth and Development Office (FCDO) through the Covid Collective. It is licensed for non-commercial purposes only. Except where otherwise stated, it is licensed for non-commercial purposes under the terms of the Open Government

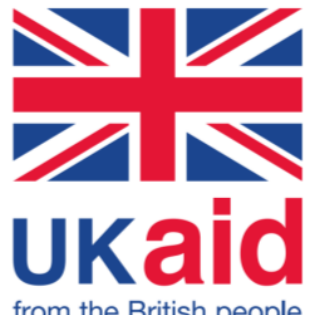
Licence v3.0. Covid Collective cannot be held responsible for errors, omissions or any consequences arising 
from the use of information contained. Any views and opinions expressed do not necessarily reflect those of FCDO, Covid Collective or any other contributing organisation.

(C) Crown copyright 2021. 